\title{
Association of Glycosylated Hemoglobin Levels With Vitamin D Status
}

\author{
Badurudeen Mahmood Buhary ${ }^{\mathrm{a}}$, Ohoud Almohareb ${ }^{\mathrm{a}}$, Naji Aljohania, b, Saleh Alrajhi ${ }^{\mathrm{a}}$, \\ Samer Elkaissi ${ }^{a}$, Suphia Sherbeeni ${ }^{\mathrm{a}}$, Abdulrahman Almaghamsia, \\ Shawana Abdulhamid Khan ${ }^{\text {a }}$, Mussa H. Almalkia, b, c
}

\begin{abstract}
Background: The discovery of vitamin D is one of medicine's great achievements. Despite all the positive evidence emerging about the beneficial effect of vitamin D, we still find many are vitamin D deficient. The purposes of this study were to examine the association between serum 25-hydroxyvitamin D $(25(\mathrm{OH}) \mathrm{D})$ and glycosylated hemoglobin $(\mathrm{HbA1c})$ levels, to test the hypothesis that lower $25(\mathrm{OH})$ $\mathrm{D}$ levels are associated with poorer glucose control in diabetes mellitus (DM) patients and to investigate the effect of vitamin D supplementation on HbAlc levels.
\end{abstract}

Methods: This was a prospective observational cohort study of all patients with type 1 and type 2 diabetes (above 12 years) who attended the outpatient clinics of a tertiary center in Riyadh. HbAlc and vitamin D levels were recorded prior to supplementation and after 9 months of supplementation with vitamin D. All patients were divided into four groups according to their vitamin $\mathrm{D}$ level and an association between $25(\mathrm{OH}) \mathrm{D}$ and $\mathrm{HbA} 1 \mathrm{c}$ was tested.

Results: Results showed that $73.1 \%$ of the patients had $25(\mathrm{OH}) \mathrm{D}$ levels $<50 \mathrm{nmol} / \mathrm{L}$. We observed lowering of HbA1c after vitamin D supplementation (from mean HbAlc of 10.55 to 7.70). We found $\mathrm{HbA1}$ c to be inversely related to serum vitamin D levels $(\mathrm{r}=-0.14(\mathrm{P}$ $<0.0000002)$ before supplementation and $-0.16(\mathrm{P}<0.000001)$ after supplementation with vitamin D).

Conclusions: Advising patients with higher HbAlc to test their vitamin D level and correct any deficiency will result in better blood glucose control and benefit the patient's overall health.

Keywords: Vitamin D; Glycosylated hemoglobin; Type 1 diabetes mellitus; Type 2 diabetes mellitus

Manuscript submitted October 11, 2017, accepted October 23, 2017

a Obesity, Endocrine and Metabolism Center, King Fahad Medical City (KFMC), Riyadh, Saudi Arabia

bKing Fahad Medical City, College of Medicine, King Saud bin Abdulaziz University for Health Science, Riyadh, Saudi Arabia

${ }^{\mathrm{c} C o r r e s p o n d i n g ~ A u t h o r: ~ M u s s a ~ H . ~ A l m a l k i, ~ O b e s i t y, ~ E n d o c r i n e ~ a n d ~ M e t a b o-~}$ lism Center, King Fahad Medical City (KFMC), Riyadh, Saudi Arabia.

Email:m2malki@yahoo.com

doi: https://doi.org/10.14740/jocmr3227w

\section{Introduction}

The discovery of vitamin $\mathrm{D}$ is one of medicine's great achievements. Vitamin D is classed as a vitamin even though recent findings showed that vitamin D is truly a prohormone [1]. If we step away from the fact that vitamin D is a vitamin and look at the bigger picture, it has huge potential in many areas.

Despite all the positive evidence emerging about the beneficial effect of vitamin D on various diseases and its need for optimal health, we still find that many people are vitamin D deficient. Vitamin D deficiency can aggravate many diseases, is linked to predisposition of diabetes and may play a role in the development of diabetes $[2,3]$. Studies show that vitamin D affects insulin sensitivity and insulin secretion, and vitamin D deficiency may also contribute to impaired glucose tolerance.

Low levels of 25-hydroxyvitamin D (25(OH)D) have been documented among inhabitants of the Middle East where people cover themselves from the harsh sun $[4,5]$. This lifestyle habit and their natural diet of low vitamin D consumption may cause poor glucose control in diabetic patients.

\section{Purposes}

The purposes of this study were to examine the association between serum 25(OH)D and glycosylated hemoglobin (HbA1c) levels, to test the hypothesis that lower 25(OH)D levels are associated with poorer glucose control in diabetes mellitus (DM) patients, and to investigate the effect of vitamin D supplementation on $\mathrm{HbA} 1 \mathrm{c}$ levels in DM patients. Accordingly, we propose to perform a prospective cohort study of prevalence of vitamin $\mathrm{D}$ deficiency in diabetic patients as well as correlation of deficiency correction of vitamin D on patients with diabetes in Saudi Arabia.

\section{Materials and Methods}

This was a prospective observational cohort study of all patients with type 1 and type 2 diabetes aged 12 years and above (younger patients were seen by pediatric endocrinologists), who attended the outpatient clinics of a tertiary center in Riyadh from 2015 onwards. After exclusion of subjects with other comorbidities like parathyroid disease, those currently using 
Table 1. Baseline Characteristics of the Study Participants

\begin{tabular}{ll}
\hline Baseline characteristics & \\
\hline Age (years) (mean \pm SD) & $43.124 \pm 19.46$ \\
HbA1c pre-supplementation (\%) (mean \pm SD) & $10.55 \pm 2.58$ \\
Vitamin D pre-supplementation (nmol/L) (mean \pm SD) & $40.09 \pm 23.13$ \\
HbA1c post-supplementation (\%) (mean \pm SD) & $7.70 \pm 1.61$ \\
Vitamin D post-supplementation (nmol/L) (mean \pm SD) & $80.5 \pm 29.77$ \\
TSH (mIU/L) (mean \pm SD) & $2.89 \pm 2.48$ \\
FT4 (pmol/L) (mean \pm SD) & $15.89 \pm 8.08$ \\
C.Ca (mmol/L) (mean \pm SD) & $2.32 \pm 0.13$ \\
Male, N (\%) & $397(39.7 \%)$ \\
Female, N (\%) & $603(60.3 \%)$ \\
T1DM, N (\%) & $338(33.8 \%)$ \\
T2DM, N (\%) & $662(66.2 \%)$ \\
\hline
\end{tabular}

HbA1c: glycated hemoglobin; TSH: thyroid-stimulating hormone; FT4: free thyroxine; C.Ca: corrected calcium; T1DM: type 1 diabetes mellitus; T2DM: type 2 diabetes mellitus.

vitamin D or calcium and pregnancy or breastfeeding mothers, the datasheet consisted of 1,000 subjects available for the present analysis. The study was approved by the Institutional Review Board (IRB) and informed consent was obtained from all participants of the study.

\section{Variables studied}

The following variables were collected from the medical record: age, sex, type of diabetes, HbAlc result, free thyroxine (FT4), thyroid-stimulating hormone (TSH), parathyroid hormone (PTH), vitamin D level and corrected calcium level. Baseline HbA1c and vitamin D levels were recorded prior to supplementation and after a period of 9 months of supplementation with vitamin $\mathrm{D}, \mathrm{HbA} 1 \mathrm{c}$ and vitamin $\mathrm{D}$ levels were recorded once again. Patients were informed about being supplemented with vitamin D. Patients were continued with usual treatment. The serum level of $25(\mathrm{OH}) \mathrm{D}$ was measured by competitive protein-binding assay using appropriate kits (Immunodiagnostic, Bensheim, Germany). HbA1c was measured using high-performance liquid chromatography.

\section{Grouping of patients}

All patients were divided into four groups according to their vitamin D level as follows: severe deficiency $(<20 \mathrm{nmol} / \mathrm{L})$, moderate deficiency (20 - $49.99 \mathrm{nmol} / \mathrm{L})$, insufficiency (50 $74.99 \mathrm{nmol} / \mathrm{L})$ and sufficiency ( $\geq 75 \mathrm{nmol} / \mathrm{L})$. An association between $25(\mathrm{OH}) \mathrm{D}$ and $\mathrm{HbA} 1 \mathrm{c}$ was tested for the 1,000 patients categorized according to their vitamin D status. At follow-up, the patients were compared based on the HbA1c and vitamin D level at baseline and at follow-up. All participants were receiving their regular treatment with either insulin or oral hypoglycemic agents or both. After follow-up the patients were again regrouped and analyzed to find out if any patients were still deficient in vitamin D.

\section{Statistical methods}

Continuous variables are represented as mean \pm SD and percentages. One-way ANOVA or unpaired $t$-test was used to analyze the difference between means. The Chi-square test was used for categorical data comparison. Pearson correlation coefficients between continuous variables were used as a measure of association. The data obtained were statistically analyzed using SPSS version 16.0. The significance level for results was set as $\mathrm{P}<0.05$.

\section{Results}

\section{Characteristics of study population}

All patients completed the study. The baseline mean HbA1c value was $10.55 \pm 2.59$ and was $7.7 \pm 1.6$ at follow-up. The baseline mean vitamin $\mathrm{D}$ value was $40.09 \pm 23.13$ and was $80.51 \pm 29.77$ at follow-up. There were almost twice as many females to males $(60.3 \%$ vs. $39.7 \%)$ and twice as many type 2 DM patients to type $1 \mathrm{DM}$ patients $(66.2 \%$ vs. $33.8 \%)$. Other baseline characteristics are shown in Table 1.

\section{Characteristics based on vitamin $D$ value}

In order to further characterize the relation between $\mathrm{HbA} 1 \mathrm{c}$ and vitamin $\mathrm{D}$, we grouped the patients on the basis of vitamin $\mathrm{D}$ levels, there was a significant difference in the age of the patients, and the patients who were older had higher levels of vitamin $\mathrm{D}(\mathrm{P}=0.0001)$. Age and vitamin $\mathrm{D}$ levels at baseline and at follow-up were significantly correlated $(0.24, \mathrm{P}<0.00001$ 
Table 2. Baseline Characteristics Grouped on Basis of Vitamin D Levels

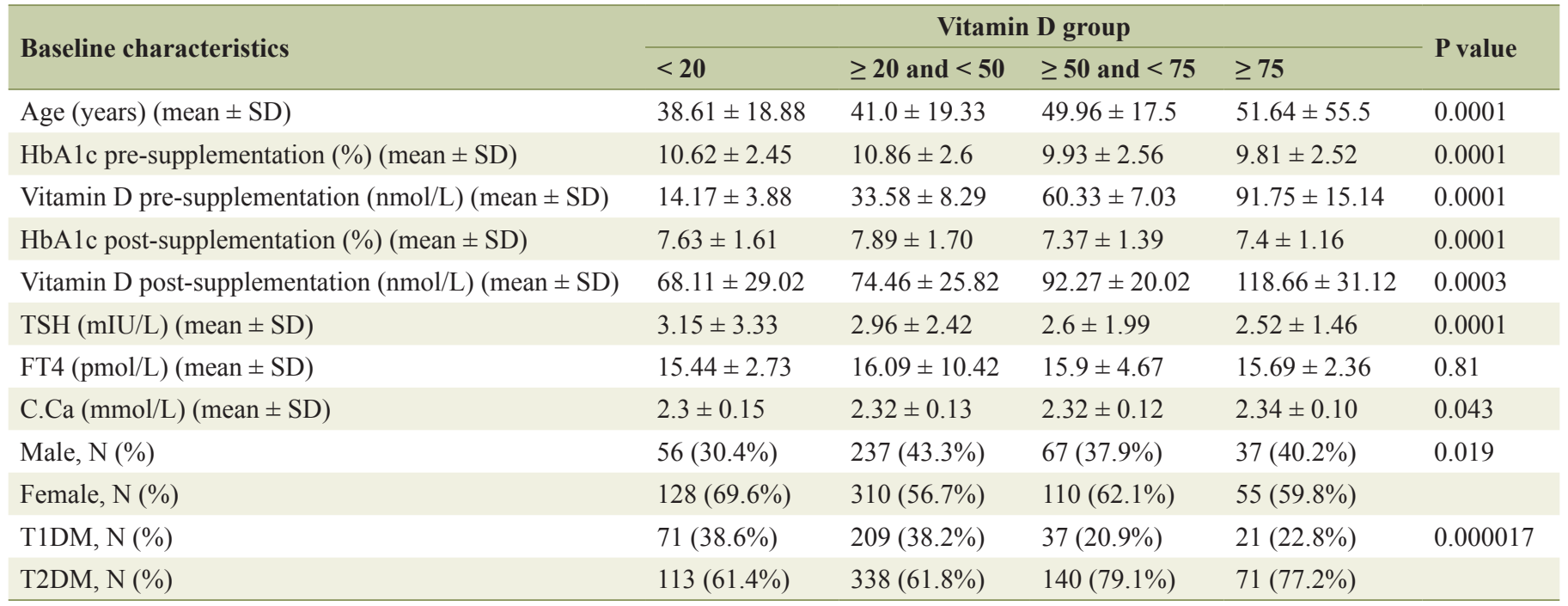

HbA1c: glycated hemoglobin; TSH: thyroid-stimulating hormone; FT4: free thyroxine; C.Ca: corrected calcium; T1DM: type 1 diabetes mellitus; T2DM: type 2 diabetes mellitus.

and 0.2, $\mathrm{P}<0.00001$, respectively) (Table 2).

Whether there is an association between $25(\mathrm{OH}) \mathrm{D}$ and HbA1c was investigated in the present study. The results showed that there was an inverse correlation between serum $25(\mathrm{OH})$ vitamin $\mathrm{D}$ and HbA1c (r (relationship coefficient $)=$ $-0.14, \mathrm{P}<0.0000002$ ) before supplementation with vitamin D. After supplementation with vitamin $\mathrm{D}$, there was still an inverse correlation between serum $25(\mathrm{OH}) \mathrm{D}$ and $\mathrm{HbA} 1 \mathrm{c}(\mathrm{r}$ $=-0.16, \mathrm{P}<0.000001)$. There was an inverse correlation between $25(\mathrm{OH}) \mathrm{D}$ and $\mathrm{HbA} 1 \mathrm{c}$ levels for each vitamin $\mathrm{D}$ group ( $<20$ group, $\mathrm{r}=-0.14, \mathrm{P}=0.05 ; \geq 20$ and $<50$ group, $\mathrm{r}=-0.13$, $\mathrm{P}=0.001 ; \geq 50$ and $<75$ group, $\mathrm{r}=-0.04, \mathrm{P}=0.08 ;$ and $\geq 75$ group, $\mathrm{r}=0.04, \mathrm{P}=0.29$ ); however, it was not significant for all groups. All these results show that there is some significant inverse correlation between serum $25(\mathrm{OH}) \mathrm{D}$ and $\mathrm{HbA} 1 \mathrm{c}$, as serum $25(\mathrm{OH}) \mathrm{D}$ goes up HbA1c comes down.

The mean HbA1c value was $10.62 \%$ in severe vitamin D deficiency, $10.86 \%$ in moderate vitamin D deficiency, $9.93 \%$ in vitamin D insufficiency and $9.81 \%$ in vitamin D sufficiency. After supplementation, we noticed significant reduction in the mean $\mathrm{HbA} 1 \mathrm{c}$ values and improvement in mean vitamin $\mathrm{D}$ value (Figs. 1 and 2). The mean HbA1c value reduced to $7.63 \%$ in severe vitamin D deficiency, $7.89 \%$ in moderate vitamin D deficiency, $7.37 \%$ in vitamin D insufficiency, and $7.4 \%$ in vitamin D sufficiency (Table 3). After regrouping the patients into groups on the basis of their vitamin D levels, there were no patients in the severe deficiency group and most patients were in the sufficiency group and there was a significant difference

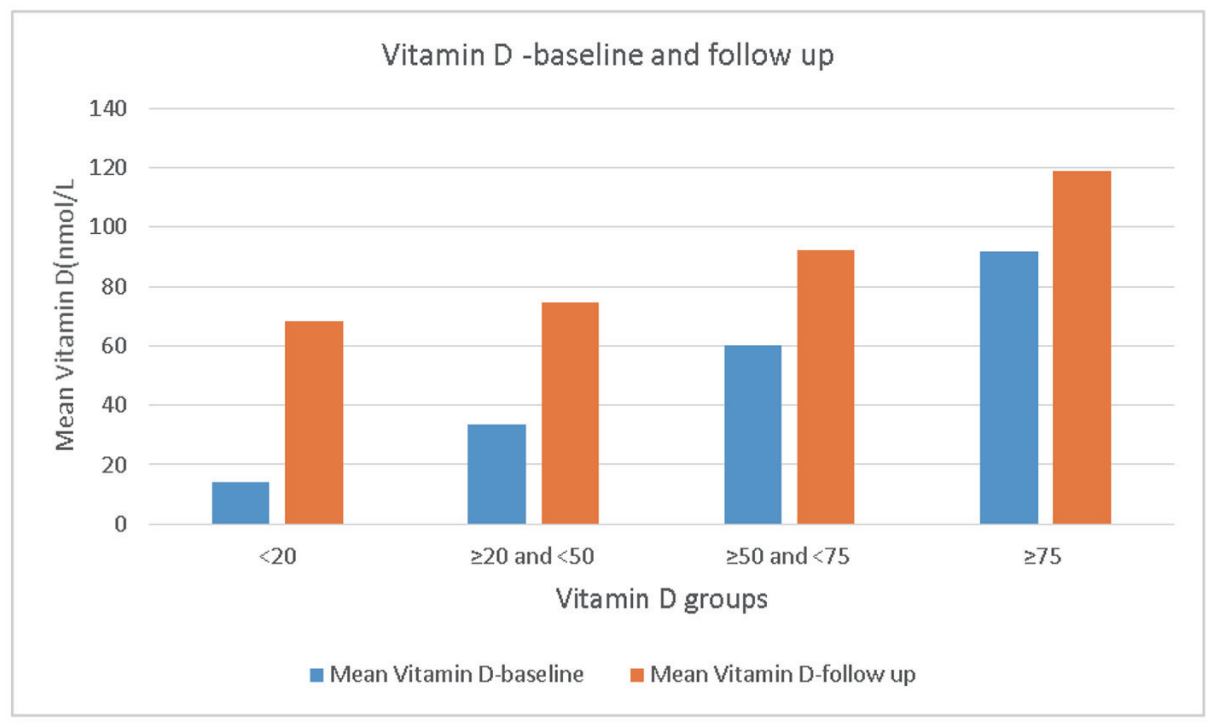

Figure 1. Vitamin D - baseline and follow-up. 


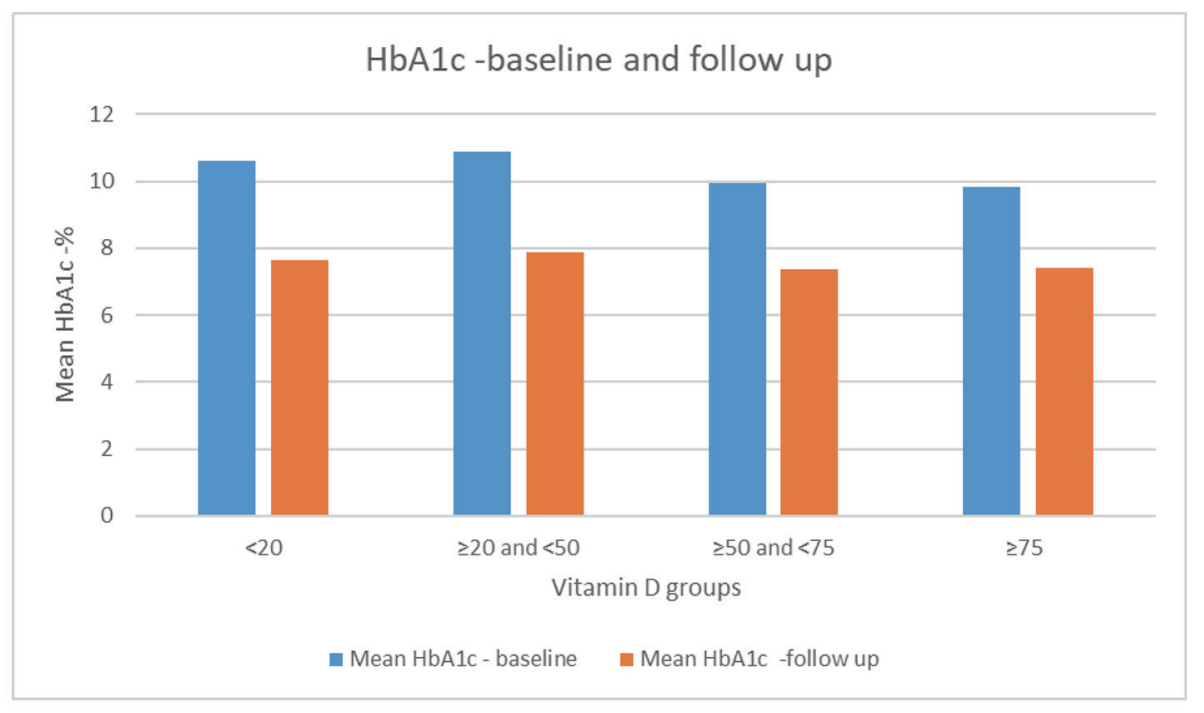

Figure 2. HbA1c - baseline and follow-up. HbA1c: glycated hemoglobin.

between the groups $(<0.00001)$ (Table 4$)$.

\section{Discussion}

In spite of the Middle East being sunny, we still find many studies reporting a deficiency in vitamin D levels among the population. A cross-sectional, school-based study carried out in all 13 regions of Saudi Arabia found 95.6\% of adolescents were vitamin D deficient [6]. Another study found a majority of Saudi medical students $(75.2 \%)$ had $25(\mathrm{OH}) \mathrm{D}$ levels $<30 \mathrm{nmol} / \mathrm{L}$, defined as risk for deficiency by the Institute of Medicine [7]. Vitamin D deficiency $(25(\mathrm{OH}) \mathrm{D}<50 \mathrm{nmol} / \mathrm{L})$ and insufficiency $(25(\mathrm{OH}) \mathrm{D}=50-74 \mathrm{nmol} / \mathrm{L})$ were reported in $50 \%$ and $43.8 \%$ in a study sample of pregnant women in a tertiary care center in Riyadh [8]. Our study reported similar findings where we found $73.1 \%$ of the patients had $25(\mathrm{OH})$ D levels $<50 \mathrm{nmol} / \mathrm{L}$. Even after supplementation, we found $16.4 \%$ of the patients had $25(\mathrm{OH}) \mathrm{D}$ levels $<50 \mathrm{nmol} / \mathrm{L}$.

An association between vitamin $\mathrm{D}$ levels and glycemic control has been reported in several studies, but the association is not consistent. Several animal and human studies suggest that vitamin $\mathrm{D}$ is a potential risk modifier for both types of diabetes $[9,10]$. Some studies conclude that vitamin D has a direct effect in improved insulin secretion and insulin action, and subsequently, improved glucose homeostasis through activation of the vitamin $\mathrm{D}$ receptor on the $\beta$-cell of the pancreas islet of Langerhans [11]. Other studies suggest vitamin $\mathrm{D}$ has an indirect role via regulation of calcium homeostasis on various mechanisms (like pancreatic beta-cell dysfunction, impaired insulin action and systemic inflammation) related to the pathophysiology of both types of diabetes [12].

A systematic review and meta-analysis reported that vitamin D and calcium insufficiency may negatively influence glycemia and that a combined supplementation of vitamin D and calcium may optimize glucose metabolism [11]. Another systematic review and meta-analysis reported a lower risk for developing type 1 diabetes with self-reported vitamin D supplementation in early childhood (odds ratio: $0.71,95 \%$ confidence interval (CI): 0.60 - 0.84) [13]. A meta-analysis of several prospective studies showed an inverse and significant association between circulating $25(\mathrm{OH}) \mathrm{D}$ levels and risk of type 2 diabetes across a broad range of blood 25(OH)D levels in diverse populations [14]. A study from Italy showed HbA1c is inversely related to serum vitamin $\mathrm{D}$ levels in type 2 diabetes patients $(\mathrm{r}=-0.116, \mathrm{P}=0.003)$ [15]. Our study also found $\mathrm{HbA} 1 \mathrm{c}$ to be inversely related to serum vitamin $\mathrm{D}$ levels $(\mathrm{r}=$ $-0.14, \mathrm{P}<0.0000002$ before supplementation and $\mathrm{r}=-0.16, \mathrm{P}$ $<0.000001$ after supplementation with vitamin $\mathrm{D}$ ).

A study from Iran showed that HbA1c may be reduced by administration of vitamin $\mathrm{D}$ to children and adolescents with type $1 \mathrm{DM}$ without changing the dose of insulin [16]. A 3-year

Table 3. Mean Change of Vitamin D Levels and HbA1c at Follow-Up

\begin{tabular}{llllllll} 
Vitamin D & $\mathbf{n}$ & $\begin{array}{l}\text { Vitamin D baseline } \\
(\text { mean } \pm \text { SD) }\end{array}$ & $\begin{array}{l}\text { HbA1c baseline } \\
(\text { mean } \pm \text { SD) }\end{array}$ & $\begin{array}{l}\text { Vitamin D follow- } \\
\text { up (mean } \pm \text { SD) }\end{array}$ & $\begin{array}{l}\text { HbA1c follow- } \\
\text { up (mean } \pm \text { SD) }\end{array}$ & $\begin{array}{l}\text { Mean change vi- } \\
\text { tamin D (P value) }\end{array}$ & $\begin{array}{l}\text { Mean change } \\
\text { HbA1c }(P \text { value }\end{array}$ \\
\hline$<20$ & 184 & $14.17 \pm 3.89$ & $10.62 \pm 2.45$ & $68.11 \pm 29.02$ & $7.63 \pm 1.61$ & $+53.94(0.0001)$ & $-2.99(0.0001)$ \\
$\geq 20$ and $<50$ & 547 & $33.58 \pm 8.23$ & $10.86 \pm 2.6$ & $74.46 \pm 25.84$ & $7.89 \pm 1.7$ & $+40.88(0.0001)$ & $-2.97(0.0001)$ \\
$\geq 50$ and $<75$ & 177 & $60.33 \pm 7.03$ & $9.93 \pm 2.56$ & $92.27 \pm 20.02$ & $7.37 \pm 1.39$ & $+31.94(0.0001)$ & $-2.56(0.0001)$ \\
$\geq 75$ & 92 & $91.75 \pm 15.14$ & $9.81 \pm 2.52$ & $118.66 \pm 31.12$ & $7.4 \pm 1.16$ & $+26.91(0.0001)$ & $-2.41(0.0001)$ \\
\hline
\end{tabular}

HbA1c: glycated hemoglobin. 
Table 4. Coefficient of Correlation Between Groups

\begin{tabular}{llllll}
\hline Vitamin D & $\mathbf{n}$ & $\begin{array}{l}\text { Vitamin D follow-up } \\
(\text { mean } \pm \text { SD) }\end{array}$ & $\begin{array}{l}\text { HbA1c post-supplementation } \\
(\text { mean } \pm \text { SD) }\end{array}$ & Coefficient of correlation & P value \\
$\geq 20$ and $<50$ & 164 & $41.34 \pm 5.35$ & $7.95 \pm 1.70$ & -0.02 & 0.79 \\
$\geq 50$ and $<75$ & 288 & $62.94 \pm 7.33$ & $8.03 \pm 1.84$ & 0 & 0.97 \\
$\geq 75$ & 548 & $101.5 \pm 22.83$ & $7.46 \pm 1.39$ & -0.1 & 0.02 \\
\hline
\end{tabular}

HbA1c: glycated hemoglobin.

study done in the US found a significant reduction in $\mathrm{HbAlc}$ levels from year 1 to year 2 and between year 1 and year 3 after supplementation of vitamin D in type 2 African American diabetic patients [17]. A study done in Saudi Arabia reported that there was an observed effect after 12 weeks of vitamin D supplementation on glycemic control in vitamin D - replete, type 1 DM patients [18]. Our study concurs with all these studies and we observed lowering of $\mathrm{HbA} 1 \mathrm{c}$ after supplementation of vitamin D (Table 3).

Another systematic review done on 29 randomized control trials $(3,324$ participants) that assessed the relationship between vitamin D supplementation and change in HbA1c and fasting blood glucose (FBG) among adults with type 2 diabetes found there was a modest reduction in $\mathrm{HbA} 1 \mathrm{c}(-0.32 \%$ $(-0.53$ to -0.10$\left.), \mathrm{I}^{2}=91.9 \%\right)$ compared to placebo after vitamin D supplementation [19]. In studies achieving repletion of vitamin $\mathrm{D}$ deficiency $(\mathrm{n}=7)$, there were greater mean reductions in HbAlc $(-0.45 \%$ (-1.09 to 0.20$))$ and FBG $(-7.64 \mathrm{mg} /$ dL (-16.25 to 0.97$))$ although not significant.

A recent systematic review and meta-analysis of relevant prospective studies till January 2017 was studied to determine the effect of vitamin D supplementation and improved vitamin D status on glycemia and insulin resistance in type 2 diabetic patients [20]. From a total of 844 entries identified via literature search, 24 controlled trials (1,528 individuals diagnosed with type 2 diabetes) evaluating the impact of vitamin D supplementation on $\mathrm{HbA1c}$, serum fasting plasma glucose (FPG), and homeostatic model assessment of insulin resistance (HOMA-IR) in diabetic patients were included.

The meta-analysis indicated a significant reduction in HbA1c (mean difference: $-0.30 \%$; 95\% CI: -0.45 to $-0.15, \mathrm{P}$ <0.001), FPG (mean difference: $-4.9 \mathrm{mg} / \mathrm{dL}(-0.27 \mathrm{mmol} / \mathrm{L})$; $95 \% \mathrm{CI}:-8.1$ to $-1.6(-0.45$ to $-0.09 \mathrm{mmol} / \mathrm{L}), \mathrm{P}=0.003)$, and HOMA-IR (mean difference: $-0.66 ; 95 \% \mathrm{CI}$ : -1.06 to $-0.26, \mathrm{P}$ $=0.001$ ) following vitamin $\mathrm{D}$ supplementation and significant increase in serum $25(\mathrm{OH}) \mathrm{D}$ levels (overall increase of $17 \pm 2.4$ $\mathrm{ng} / \mathrm{mL}(42 \pm 6 \mathrm{nmol} / \mathrm{L}))$.

The meta-analysis concluded that a minimum dose of 100 $\mu \mathrm{g} /$ day (4,000 IU/day) of vitamin D supplementation may significantly reduce serum FPG, HbAlc, and HOMA-IR index, and helps to control glycemic response and improve insulin sensitivity in type 2 diabetic patients [20].

Our study strongly concurs with these systematic reviews as we also found that there was a significant reduction in $\mathrm{HbA} 1 \mathrm{c}$ (mean difference: $-2.848 \%$; 95\% CI: -3.04 to $-2.66, \mathrm{P}<0.001$ ).

The need of accurate and precise measurement of blood glucose has made $\mathrm{HbA} 1 \mathrm{c}$ become the gold standard for monitoring glycemic control in patients with DM from primarily fasting plasma [21]. Endorsement of influential diabetes societies and the World Health Organization for using HbAlc as a diagnostic test for diabetes arose due to the clear advantages for HbA1c over glucose monitoring (and in particular oral glucose tolerance test (OGTT)) [22]. Vitamin D supplementation to help reduce $\mathrm{HbA} 1 \mathrm{c}$ values will result in overall better health and improve glycemic outcomes in patients with diabetes. Our study also noted that the group with better vitamin D levels were older maybe due to better diet and lifestyle pattern $(\mathrm{P}=$ 0.0001). Poor diet, less time spent outdoors, and the consumption of more processed food by the younger generation can be a major contributor to their lower vitamin D levels.

Improvement in diet or vitamin D supplementation with added exposure to sunlight at the optimal sun exposure time [23] may improve vitamin D levels with additional benefit to the patient's overall health.

\section{Conclusions}

In conclusion, there is a significant inverse association between serum $25(\mathrm{OH}) \mathrm{D}$ and $\mathrm{HbA} 1 \mathrm{c}$. The important result we find from this study is a significant reduction in $\mathrm{HbA} 1 \mathrm{c}$ as vitamin D levels increased. The percentage of vitamin D deficiency in the population and the growth of diabetes in the population suggest that repletion can improve overall health. There is so much benefit to be gotten from supplementation with vitamin $\mathrm{D}$ or by adding natural vitamin $\mathrm{D}$ rich food in the diet and including physical activities with possible sun light exposure. Advising patients with higher HbA1c to get tested for lower vitamin D values and correct any deficiency if found may result in better blood glucose control and benefit the patient's overall health.

\section{Competing Interests}

None.

\section{Grant Support}

None.

\section{References}

1. DeLuca HF. Overview of general physiologic features and functions of vitamin D. Am J Clin Nutr. 2004;80(6 
Suppl):1689S-1696S.

2. Pittas AG, Nelson J, Mitri J, Hillmann W, Garganta C, Nathan DM, Hu FB, et al. Plasma 25-hydroxyvitamin D and progression to diabetes in patients at risk for diabetes: an ancillary analysis in the Diabetes Prevention Program. Diabetes Care. 2012;35(3):565-573.

3. Hutchinson MS, Figenschau Y, Njolstad I, Schirmer H, Jorde R. Serum 25-hydroxyvitamin D levels are inversely associated with glycated haemoglobin $(\operatorname{HbA}(1 \mathrm{c}))$. The Tromso Study. Scand J Clin Lab Invest. 2011;71(5):399406.

4. Elsammak MY, Al-Wosaibi AA, Al-Howeish A, Alsaeed J. Vitamin d deficiency in Saudi Arabs. Horm Metab Res. 2010;42(5):364-368.

5. Bener A, Al-Ali M, Hoffmann GF. High prevalence of vitamin D deficiency in young children in a highly sunny humid country: a global health problem. Minerva Pediatr. 2009;61(1):15-22.

6. AlBuhairan FS, Tamim H, Al Dubayee M, AlDhukair S, Al Shehri S, Tamimi W, El Bcheraoui C, et al. Time for an adolescent health surveillance system in Saudi Arabia: Findings From "Jeeluna". J Adolesc Health. 2015;57(3):263-269.

7. BinSaeed AA, Torchyan AA, AlOmair BN, AlQadhib NS, AlSuwayeh FM, Monshi FM, AlRumaih FI, et al. Determinants of vitamin D deficiency among undergraduate medical students in Saudi Arabia. Eur J Clin Nutr. 2015;69(10):1151-1155.

8. Al-Faris NA. High prevalence of vitamin D deficiency among pregnant Saudi women. Nutrients. 2016;8(2):77.

9. Mitri J, Pittas AG. Vitamin D and diabetes. Endocrinol Metab Clin North Am. 2014;43(1):205-232.

10. Pittas AG, Dawson-Hughes B. Vitamin D and diabetes. J Steroid Biochem Mol Biol. 2010;121(1-2):425-429.

11. Pittas AG, Lau J, Hu FB, Dawson-Hughes B. The role of vitamin $\mathrm{D}$ and calcium in type 2 diabetes. A systematic review and meta-analysis. J Clin Endocrinol Metab. 2007;92(6):2017-2029.

12. Al-Shoumer KA, Al-Essa TM. Is there a relationship between vitamin $\mathrm{D}$ with insulin resistance and diabetes mellitus? World J Diabetes. 2015;6(8):1057-1064.

13. Zipitis CS, Akobeng AK. Vitamin D supplementation in early childhood and risk of type 1 diabetes: a systematic review and meta-analysis. Arch Dis Child. 2008;93(6):512-517.

14. Song Y, Wang L, Pittas AG, Del Gobbo LC, Zhang C, Manson JE, Hu FB. Blood 25-hydroxy vitamin D levels and incident type 2 diabetes: a meta-analysis of prospective studies. Diabetes Care. 2013;36(5):1422-1428.

15. Zoppini G, Galletti A, Targher G, Brangani C, Pichiri I, Negri C, Stoico V, et al. Glycated haemoglobin is inversely related to serum vitamin $\mathrm{D}$ levels in type 2 diabetic patients. PLoS One. 2013;8(12):e82733.

16. Ordooei M, Shojaoddiny-Ardekani A, Hoseinipoor SH, Soleimanizad R, Miroliai M, Zare-Zardini H. Effect of vitamin D on hbalc levels of children and adolescents with diabetes mellitus type 1. Minerva Pediatr. 2017;69(5):391-395.

17. Green RT, Gambhir KK, Nunlee-Bland G, Odonkor WA, Ganta VA. Maintenance of long-term adequate levels of vitamin d lowers HbAlc in African American patients with type 2 diabetes. Ethn Dis. 2014;24(3):335-341.

18. Aljabri KS, Bokhari SA, Khan MJ. Glycemic changes after vitamin D supplementation in patients with type 1 diabetes mellitus and vitamin D deficiency. Ann Saudi Med. 2010;30(6):454-458.

19. Lee CJ, Iyer G, Liu Y, Kalyani RR, Bamba N, Ligon CB, Varma $\mathrm{S}$, et al. The effect of vitamin $\mathrm{D}$ supplementation on glucose metabolism in type 2 diabetes mellitus: A systematic review and meta-analysis of intervention studies. J Diabetes Complications. 2017;31(7):1115-1126.

20. Mirhosseini N, Vatanparast H, Mazidi M, Kimball SM. The effect of improved serum 25-Hydroxyvitamin D status on glycemic control in diabetic patients: A MetaAnalysis. J Clin Endocrinol Metab. 2017;102(9):30973110.

21. Higgins T. HbA1c for screening and diagnosis of diabetes mellitus. Endocrine. 2013;43(2):266-273.

22. Florkowski C. HbA1c as a diagnostic test for diabetes mellitus - reviewing the evidence. Clin Biochem Rev. 2013;34(2):75-83.

23. Alamri F, Alshahrani F, Al-Saleh Y, Saeedi MY, Almalki MH, Al-Daghri N, Alzahrani A, Holick M, Ibrahim AK. Optimum sun exposure times for vitamin d status correction in Saudi Arabia. European Journal of Preventive Medicine. 2015;3(5):147. 